\title{
Abnormal ECG Findings in Athletes: Clinical Evaluation and Considerations
}

\author{
Mark Abela, MD (Melit), MRCP, MSc Sports Cardiology (Lond), \\ MSc Internal Medicine (Edin) $)^{1,2, *}$ \\ Sanjay Sharma, BSC, MD, FRCP, FESC ${ }^{1}$
}

\author{
Address \\ ${ }^{*}, 1$ Cardiology Clinical Academic Group, St. George's, University of London, St. \\ George's University Hospitals NHS Foundation Trust, London, UK \\ Email: markabela88@gmail.com \\ ${ }^{2}$ University of Malta, Msida, Malta
}

Published online: 21 December 2019

(C) The Author(s) 2019

This article is part of the Topical Collection on Sports Cardiology

Keywords Athlete $\cdot$ Electrocardiogram · Screening $\cdot$ Evaluation · Arrhythmia $\cdot$ Sudden cardiac death

\begin{abstract}
Purpose of review Pre-participation cardiovascular evaluation with electrocardiography is normal practice for most sporting bodies. Awareness about sudden cardiac death in athletes and recognizing how screening can help identify vulnerable athletes have empowered different sporting disciplines to invest in the wellbeing of their athletes.

Recent findings Discerning physiological electrical alterations due to athletic training from those representing cardiac pathology may be challenging. The mode of investigation of affected athletes is dependent on the electrical anomaly and the disease(s) in question. Summary This review will highlight specific pathological ECG patterns that warrant assessment and surveillance, together with an in-depth review of the recommended algorithm for evaluation.
\end{abstract}

\section{Introduction}

Suddenty cardiac death (SCD) in athletes is the leading cause of mortality during intense physical activity $[1 \bullet]$. The precise incidence of such tragedies has been difficult to ascertain due to differences in methodologies and the heterogenous nature of the populations studied. Current studies report an incidence ranging from 0.5 to 13 deaths per 100,000 athletes [2-4], with a greater number of deaths occurring in older ( $\geq 35$ years) athletes. Most deaths affect males and usually occur during or immediately after exercise, suggesting that exercise is a trigger 
for fatal arrhythmias in vulnerable athletes. The majority of cardiac disorders implicated in SCD can be broadly categorised into structural or electrical diseases, which may be genetic, congenital or acquired. Among young athletes ( $<35$ years old), death is usually due to genetic or congenital diseases such as the cardiomyopathies, coronary artery anomalies, ion-channel disease or electrical accessory pathways. Coronary artery disease is the predominant cause of death in older athletes. Up to $80 \%$ of SCDs occur without any pre-warning signs [5, 6]; therefore, some form of screening process is necessary to identify high-risk athletes on the assumption that early identification of clinically silent cardiovascular disease empowers physicians to implement strategies to prevent SCD. Given the diverse spectrum of diseases implicated in exercise-related SCD, an elaborate investigation protocol would be necessary to identify most athletes. Such an approach would be cost prohibitive because SCD in sports is rare.

The most pragmatic and cheapest method is to screen with a health questionnaire and physical examination as recommended by the American Heart Association, but this approach is associated with poor sensitivity because most athletes are asymptomatic prior to death. The 12-lead electrocardiogram (ECG) is the simplest diagnostic tool in cardiology and is effective at detecting a number of disorders linked to SCD, including ion-channel disorders, electrical accessory pathways and cardiomyopathies [7]. The Italian experience first shed light on the importance of the ECG during screening of athletes more than a decade ago, with abnormal ECG findings more commonly found in athletes who died of a cardiomyopathy (86\%) [8].

Variability in disease penetrance is well recognised with inherited cardiomyopathies, and early preclinical manifestations may only be visible on an ECG, years before any overt clinical findings.
Abnormal findings may become evident several years after screening as a result of disease progression [9]. A longitudinal study of athletes with T-wave inversion (TWI) showed that $6 \%$ of athletes with abnormal ECGs develop a cardiomyopathy after $12 \pm 5$ years [10]. One of the main concerns about ECG screening in athletes is the number of false-positive tests. Over the past decade, there have been several evidencebased refinements in ECG interpretation criteria that recognise the impact of age, ethnicity and type and intensity of sporting discipline on the electrical manifestation of the athlete's heart $[1 \bullet, 11 \bullet, 12]$. The most current international recommendations are associated with only $3 \%$ positive tests in white athletes and $2 \%$ in white adolescents, without compromising specificity $[1 \bullet, 11 \bullet, 13]$.

On occasion, athletes exhibit profound electrical repolarisation anomalies, such as TWI that overlaps with those observed in patients with cardiomyopathy. Similarly, some athletes show a long QT interval or incomplete right bundle branch block (RBBB) with J-point elevation in the absence of symptoms or a relevant family history of long QT syndrome (LQTS) and Brugada syndrome respectively. Such athletes are investigated comprehensively according to established protocols and may train intensively and compete in the absence of a definitive diagnosis. Given that some of these athletes could possibly harbour incomplete phenotypic expression of serious disease, regular monitoring is recommended and such athletes should be warned about the symptoms of cardiac disease.

The aim of this review is to highlight the investigation and subsequent surveillance of athletes with abnormal ECG patterns, focusing on controversial aspects and gaps in the literature. This review will also focus on more novel ECG patterns that may simulate disease.

\section{The athlete's electrocardiogram}

Individuals who engage in at least 4 hours of intensive physical activity every week undergo structural, functional and electrical adaptations within the heart that help accommodate the increased demand in cardiac output [14]. High vagal tone and increased cardiac dimensions are responsible for a number of physiological ECG changes [1•]. Different demographic factors influence the degree and type of electrical adaptations, including age, gender, ethnicity and sporting disciplines [15]. Up to $80 \%$ of highly trained 
a

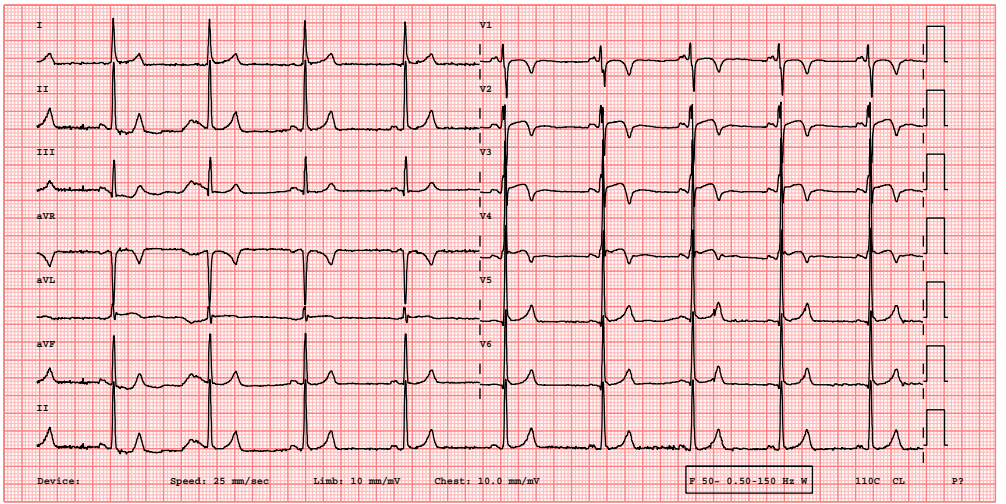

b

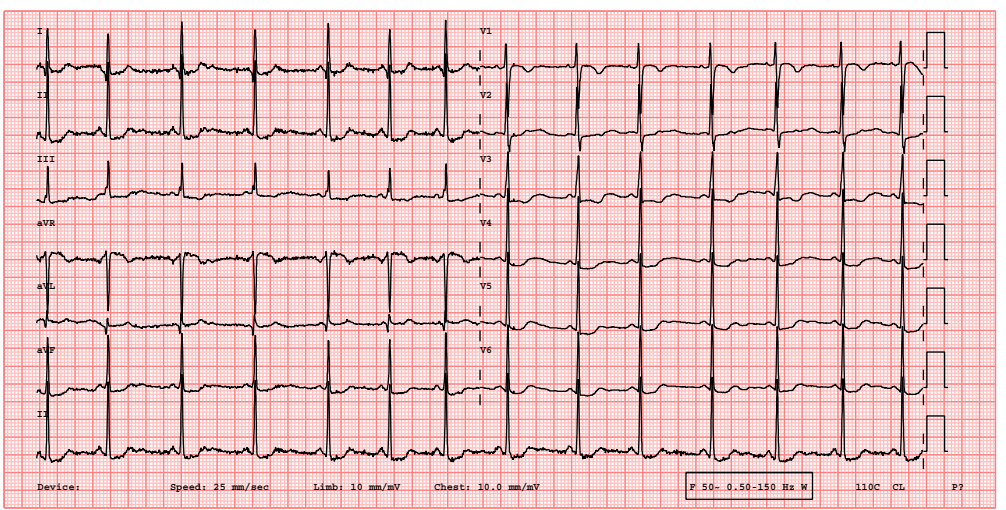

C

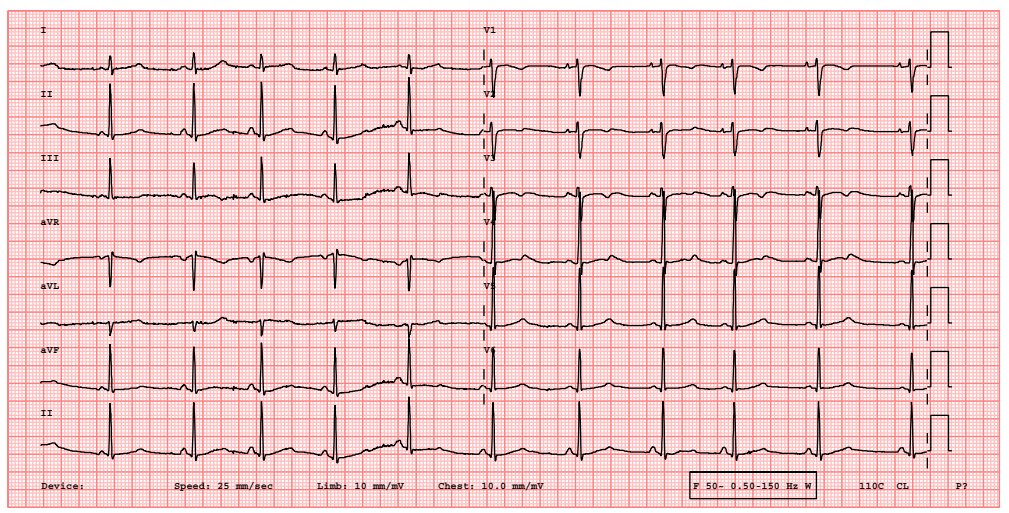

Fig. 1. a Adolescent football player with anterior T-wave inversions and no clinical phenotype. b A basketball player with diffuse ST depressions identified at screening with no clear phenotype who remains under surveillance. $\mathbf{c}$ A young competitive swimmer with notched T waves and long QT supporting a diagnosis of LQTS. $\mathbf{d}$ Professional basketball player with a hypertrophic cardiomyopathy phenotype. e Recreational athlete complaining of palpitations, found to have right ventricular outflow tract ectopy in the absence of structural heart disease. $\mathbf{f}$ Asymptomatic football player with classical Wolff-Parkinson-White pattern. 
d

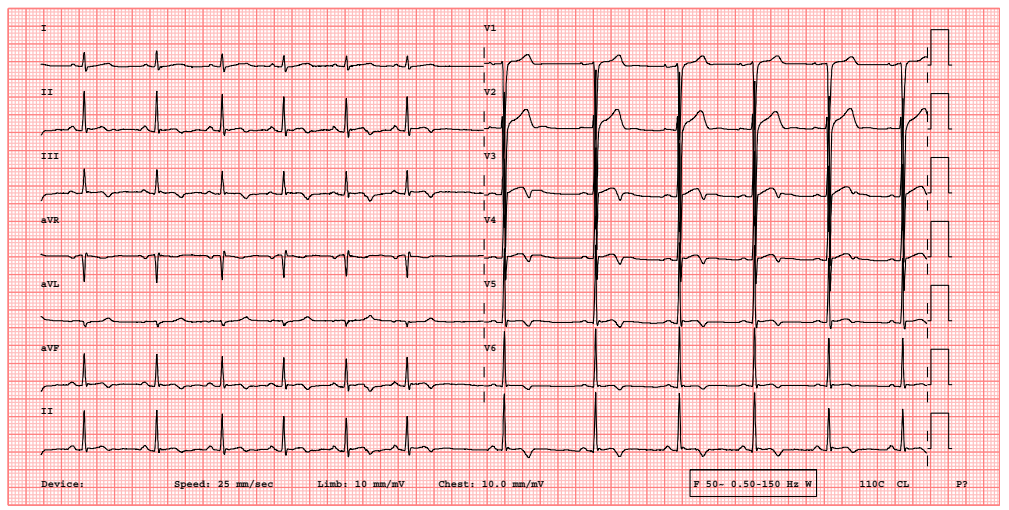

e
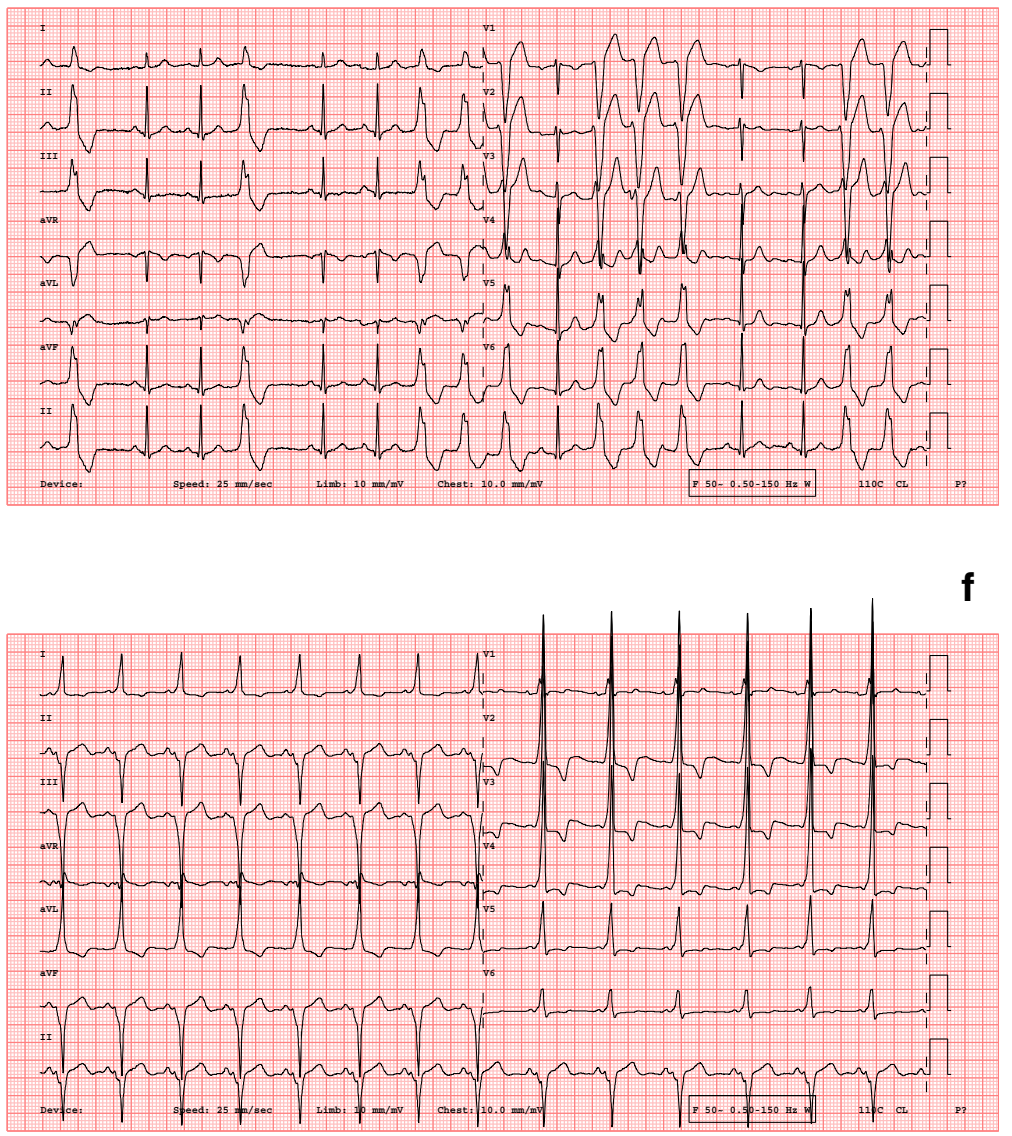

Fig. 1. (Continued) 
athletes will have sinus bradycardia [16]. Over $70 \%$ will manifest repolarisation changes, causing J-point and ST segment elevation [17]. Almost 50\% will satisfy ECG voltage criteria for left ventricular hypertrophy [18] and $12 \%$ for right ventricular hypertrophy [19]. Incomplete RBBB is identified in almost 20\% [20], first-degree atrioventricular block (AVB) in $7 \%$ [17] and isolated axis deviation in $2 \%$ of healthy athletes [17, 19, 21, 22].

A proportion of athletes do however manifest ECG patterns that overlap with cardiac pathology, including repolarisation and depolarisation abnormalities, ventricular ectopy and high-degree AVB. Given the potential consequences of failing to identify a serious cardiac condition, several systematic algorithms are available to investigate such athletes. In the absence of overt disease, annual surveillance is recommended whilst the athlete is competing. Assessment of first-degree relatives may provide invaluable clues about possible underlying pathology.

\section{Dealing with pathological ECG findings in athletes}

Different clinical phenotypes will present with a variety of electrical anomalies, and some electrical patterns are diagnostic (Fig. 1). Evidence regarding disease progression and arrhythmic risk in most cardiovascular disorders in athletes is limited. We recommend a holistic approach, focusing on identification of the clinical phenotype and risk stratification at rest and/or during exercise. In some cases, detraining may be required to ascertain the significance of profound repolarisation anomalies such as TWI.

Among healthy athletes, first-degree and Mobitz type 1 second-degree AVB reflect high vagal tone at the atrioventricular (AV) node, with or without intrinsic involvement of the AV node. High-grade AVB, including Mobitz type 2 and complete heart block, are rare and should be considered as a manifestation of cardiac disease.

Pathological AVB in young athletes may occur secondary to infective myocarditis (Lyme's disease, Chagas disease), immune diseases (cardiac sarcoidosis) and genetic disorders (PRKAG2 syndrome, myotonic dystrophy, laminin A/C dilated cardiomyopathy). Relevant serology, genetic and imaging evaluations should thus be performed, depending on the clinical scenario [1•]. Among older and middle-aged athletes, cardiac conduction disease is the most likely aetiology.

Clinical evaluation: Nodal AV block is a manifestation of the athlete's heart, typically in the presence of a narrow QRS with an adequate heart rate response during exercise. Sinus pauses exceeding $3 \mathrm{~s}$ were previously considered as a pathological variant, though this has now been disregarded [23]. AVB at or below the bundle of His (infra-hissian [nodal] AV block) should always be considered pathological. A broad QRS, an abnormal axis and an inadequate 
increase in sinus rate response during exercise are useful in confirming conduction disease. Further evaluation should be carried out to ascertain the aetiology and risk. Resolution of AVB with appropriate chronotropic response during exercise implies low risk. Holter monitoring and echocardiography are necessary if response to exercise is unsatisfactory. A case-by-case assessment is recommended when considering pacemaker implantation, which is dependent on the site of the AV block, the aetiology and the symptomatic status.

\section{Ventricular depolarisation abnormalities}

\section{Ventricular pre-excitation}

Ventricular pre-excitation (Wolff-Parkinson-White syndrome (WPW)) occurs when antegrade conduction from the atria to the ventricles takes place preferentially via a congenital accessary pathway and bypasses the AV node [13]. WPW is present in 0.1 to $0.3 \%$ of athletic and non-athletic individuals [24]. It may potentially serve as a substrate for SCD in certain environmental conditions which alter the physiology of the accessory pathway (electrolytes, temperature, $\mathrm{pH}$ ). The SCD rate in patients with WPW is rare at $0.1 \%$ per patient year and is up to fourfold higher in symptomatic individuals $[24,25]$. Individuals who engage in intense physical activity are at a higher risk of developing malignant ventricular arrhythmias, and SCD $[26,27]$.

Ventricular pre-excitation may be associated with atrioventricular re-entrant tachycardia which is usually benign. Aberrant pathways may also serve as substrates for malignant ventricular arrythmias when co-existing with atrial fibrillation [28]. WPW syndrome may be genetically inherited in $2-4 \%$ of cases, and may also be associated with Ebstein's anomaly and syndromic hypertrophic cardiomyopathy (HCM) due to glycogen storage disorders, most notably due to mutations in the gamma 2 subunit of adenosine monophosphateactivated protein kinase (PRKAG2) [29-31].

Clinical evaluation: The evaluation and management options for athletes with WPW are still debatable. Current consensus recommends starting with non-invasive risk stratification. An abrupt and complete loss of preexcitation during an exercise test suggests a low-risk pathway [32, 33]. Intermittent pre-excitation during sinus rhythm on a resting ECG is also regarded as a low-risk abnormality $[1 \bullet, 34]$. Excluding structural heart disease with echocardiography is recommended. An electrophysiological study (EPS) is preferred if non-invasive testing is inconclusive and is helpful in determining the shortest pre-excited RR interval (SPERRI) during atrial fibrillation or rapid atrial pacing. SPERRI measures antegrade conduction through the accessory pathway. Catheter ablation is recommended in patients with a SPERRI of $\leq 250 \mathrm{~ms}(240 \mathrm{bpm})$, suggesting the accessory pathway is able to serve as a malignant substrate [32]. The role for EPS as a first-line diagnostic tool in asymptomatic individuals is debatable. There 
are no randomised studies comparing the event rates in those undergoing EPS and ablation versus those followed up clinically. EPS may nevertheless be a first-line option for all competitive athletes who engage in moderate or high-intensity exercise, irrespective of symptoms or risk, as one cannot guarantee the same pathway conductance during bouts of high catecholamine surges, which are difficult to replicate with non-invasive testing [1・]. Moreover, athletes are at an increased risk of atrial fibrillation, which itself may pose a risk for SCD if the accessory pathway has the potential for fast antegrade conduction [27]. The latest ESC guidelines on the management of supraventricular tachycardia provide a class I recommendation for investigating individuals in high-risk occupations (including athletes) with EPS and ablating the accessory pathway.

\section{Pathological Q waves}

There has been a lack of consensus relating to the definition of a pathological Q wave. Revised criteria now define a pathological Q wave as a negative deflection (deep or wide) exceeding $\geq 40 \mathrm{~ms}$ or one which has an amplitude $\geq 25 \%$ of the following R wave in two contiguous leads (excluding aVR, III and $\mathrm{aVL}$ ). A duration of $\geq 30 \mathrm{~ms}$ in lead I appeared to offer the greatest discriminatory value to distinguish athletes from patients with HCM in one study [35]. Ensuring good lead positioning will help decrease the falsepositive rates as lead misplacement is a common reason for such a pattern [35].

Pathological Q waves are frequently observed in non-ischaemic cardiomyopathy, myocardial infiltration or infarction. They are also present in 1-2\% of apparently healthy athletes where they are localised to the inferior and/or lateral leads and are more common in male and black athletes [35, 36].

The presence of pathological $Q$ waves warrants further investigation to exclude cardiomyopathy and myocardial scar. A cardiac magnetic resonance (CMR) imaging scan with stress perfusion imaging will identify structural disease, including scar, and check for inducible myocardial ischaemia due to coronary artery disease.

\section{QRS fragmentation}

Data about QRS fragmentation is not robust. The definition and clinical relevance of QRS fragmentation were not included in the latest recommendations for ECG interpretation [1•]. Most studies define this phenomenon as the presence of single or multiple notches in the nadir of the $\mathrm{S}$ wave, an additional $\mathrm{R}$ wave $\left(\mathrm{R}^{\prime}\right)$ or the presence of $>1$ spiked or slurred $\mathrm{R}^{\prime}$ in two contiguous leads. The location or the degree of fragmentation is however not taken into consideration, which accounts for significant inter-observer variability $[37,38]$. Precise definitions may help in this regard and enable the differentiation of QRS fragmentation from early repolarisation which is considered benign in athletes. Early repolarisation is defined as slurring or notching in the final $50 \%$ of the R wave downslope [39], whereas fragmentation takes place in the $\mathrm{S}$ wave, Q wave or first $50 \%$ of the $\mathrm{R}$ wave [38]. 
Fragmentation has been shown to be associated with myocardial scar and fibrosis [40]. Its presence in the limb leads has been linked to a higher risk for SCD in patients with dilated cardiomyopathy, arrhythmogenic cardiomyopathy, ischaemic cardiomyopathy and Brugada syndrome [4143]. The sensitivity of QRS fragmentation in isolation remains to be seen, and referral for evaluation should be based on the clinical scenario. Our own experience is to investigate asymptomatic athletes with fragmentation in the context of a familial cardiomyopathy, Brugada syndrome or sudden arrhythmic death syndrome.

\section{Low QRS voltage}

Low QRS voltage is defined as a QRS amplitude of $<0.5 \mathrm{mV}$ in all frontal leads and/or $<1.0 \mathrm{mV}$ in all precordial leads. It is present in $1-2 \%$ of normal lean individuals and has been associated with an increased mortality rate in apparently healthy individuals [44]. Our own experience suggests that small QRS complexes in the limb leads are associated with a scar within the left ventricular (LV) myocardium in symptomatic athletes, especially when precordial QRS voltages are normal. In a study of 110 athletes, those with arrhythmias were statistically more likely to have low QRS voltages if they harboured a scar compared to those without a scar [45]. Further studies are necessary to evaluate the significance of low QRS voltages even though they were not considered as a potential abnormality in the latest recommendations for ECG interpretation $[1 \bullet]$.

\section{Non-specific intraventricular conduction delay}

Non-specific intraventricular conduction delay is defined as a QRS duration of $>110 \mathrm{~ms}$ without a specific morphology. It is commonly reported in the general population. Such an anomaly is also documented in individuals with cardiomyopathy and has been linked to a higher risk of cardiovascular death [46, 47]. Its significance in athletes is unclear, but it is thought to occur because of a combination of high vagal tone and increased myocardial mass [13]. Further studies are needed to elucidate its clinical significance. At present, further evaluation is only recommended in asymptomatic athletes if the QRS is severely prolonged $>140 \mathrm{~ms}$, regardless of morphology [1•].

\section{Repolarisation abnormalities}

\section{T-wave inversion}

TWI is often regarded as the electrical hallmark pattern for cardiomyopathies, with certain patterns and distributions being more suggestive of specific conditions. TWI is also relatively common in athletes [48] and is present in up to $6 \%$ of athletes $[18,20,49]$. Abnormal TWI is defined as an inverted segment of the T wave in $\geq 2$ contiguous leads with a depth of $\geq 1 \mathrm{~mm}$, excluding leads V1, aVR and III. Despite this definition, groups vary in how they report TWI morphology, with some quoting a depth of $\geq 1 \mathrm{~mm}[18,20,22,49]$, whilst others quote a depth of $\geq 2 \mathrm{~mm}[48,50,51]$. Our own practice is to define TWI as any negative T-wave deflection because there is no evidence suggesting that a specific depth is more likely to exclude structural heart disease, nor is there 
any data on the clinical relevance of biphasic, flat or broad-based inverted $\mathrm{T}$ waves.

Anterior TWI in leads V1-V4 is a relatively common finding in young asymptomatic individuals aged $<16$ years, black athletes and some endurance athletes $[1 \bullet]$. In such cases, T waves are often asymmetric or biphasic and never associated with ST segment depression. TWI in V1-V2 is regarded as a normal variant in athletes [52]. Among a cohort of 14,646 white athletes and non-athletes, none of those referred for evaluation for anterior TWI (6.5\% of athletes) satisfied criteria for arrhythmogenic cardiomyopathy (AVC), implying that anterior TWI in isolation is non-specific for any cardiomyopathy [53].

Influence of age: Anterior TWI is reported in up to $11 \%$ of healthy adolescent athletes [22]. It is regarded as a pre-pubertal variant or "juvenile" ECG pattern in the absence of symptoms or family history $[18,22]$. The current recommendations use an age of 16 years as the cutoff for this ECG label [1•], though pubertal development (biological age) rather than chronological age seems to be independently associated with the presence of anterior TWI $[22,54]$. Right ventricular dominance and predominant posteriorly directed repolarisation in young teenagers may explain this phenomenon [55]. The prevalence of anterior TWI tends to decrease after the age of 16 , with only $0.2 \%$ manifesting anterior TWI beyond V2 when aged $\geq 16$ years $[18,22]$. Among those with a persistent juvenile ECG pattern at the age of 16, only $2 \%$ persist beyond this age [56].

Influence of sex: Anterior TWI is more common in females (4.3\% vs $1.4 \%)$ and extends beyond $\mathrm{V} 2$ in $1.2 \%$ (versus $0.2 \%$ in males) of cases [52]. Shallow TWI morphology in isolation may imply a more benign phenotype. The precise significance of this sex difference is uncertain, and it is possible that chest anatomy in post-pubertal females is conducive to Anterior TWI [53].

Influence of ethnicity: TWI is more common in black athletes [57]. Anterior TWI is present in up to $25 \%$ of Afro-Caribbean athletes [10, 51, 58]. It is considered part of the 'black athlete's heart' when preceded by J-point and concave ST segment elevation $[1 \bullet, 51]$.

Influence of sporting discipline: Anterior TWI is reported in up to $14 \%$ of endurance athletes, with electrical remodelling commencing earlier on in adolescence [59]. Biphasic or bifid TWI extending into lead V3 were reported in $4 \%$ of endurance athletes with a structurally normal heart [17]. Right ventricular (RV) remodelling and lateral displacement of the RV may explain isolated anterior TWI in these athletes [60].

Clinical evaluation: Isolated ATWI in asymptomatic children, black athletes and endurance athletes should not be over reported [61, 62]. Other ECG 
findings of AVC should be sought such as prolongation of the terminal Swave upstroke ( $\geq 55 \mathrm{~ms}$ in $\mathrm{V} 1-\mathrm{V} 3$ in the absence of right bundle branch block), ventricular ectopy, epsilon waves and low limb lead voltages [61, 63]. CMR imaging is key in the assessment of athletes with abnormal TWI because echocardiography cannot visualise the right ventricle adequately. CMR can also help identify LV involvement in such cases [64]. A number of findings have been shown to be more specific in identifying AVC in athletes [61]. All three abnormal signal averaged ECG parameters may help identify late QRS potentials specifically in athletes [61]. Arrhythmia burden and complexity are important markers of disease. Sustained or on-sustained ventricular tachycardia, multiple couplets and triplets of varying morphology and $\geq 1000$ ventricular premature beats are suggestive of AVC [61]. Furthermore, ventricular tachycardia or increase in VE frequency during stress ECG is another useful parameter [61]. A low RV fractional area change of $\leq 30 \%$ on echocardiography or $<45 \%$ on $\mathrm{CMR}$, in the presence or absence of regional wall motion abnormalities or fibrosis on CMR, is useful in diagnosing AVC [61]. All these investigations may help in the phenotypic characterisation and risk stratification of athletes where the clinical suspicion of AVC is high.

Lateral (V5/V6, I, aVL) and inferior (II, III, aVF) T-wave

inversion

Lateral TWI in two or more contiguous leads is uncommon in athletes, present in $1.5 \%$ of athletes. Lateral TWI may occur in isolation or coexist with inferior TWI [18]. Isolated lateral TWI is present in up to $6 \%$ of black athletes and $1.5 \%$ of white athletes [51]. Lateral TWI is associated with a relatively high yield for cardiomyopathies particularly in white athletes [10, 50]. The exact significance of isolated inferior TWI is unknown. Our experience suggests that isolated inferior TWI is more common in HCM than in athletes, which is why current guidelines stipulate comprehensive evaluation [1•].

Clinical evaluation: Lateral TWI is regarded as pathological until proven otherwise, irrespective of the morphology and depth of the TWI. CMR is key in establishing a diagnosis, even in the presence of normal echocardiography [50]. CMR provides superior spatial resolution to help visualise the LV apex and myocardial wall thickness and also has the additional benefit of detecting myocardial fibrosis with gadolinium. Stress ECG and Holter monitoring will also help by evaluating arrhythmic burden. Comprehensive and serial evaluation is imperative, even in the absence of a clinical diagnosis, as there is substantial evidence to development of a future cardiomyopathy in a small proportion of athletes.

\section{ST segment elevation-early repolarisation or Brugada syndrome?}

ST segment elevation in the chest leads, often in combination with J-point elevation, is common in athletes and present in up to $45 \%$ of white athletes and $90 \%$ of black athletes $[18,51]$. This pattern may overlap with the Brugada ECG pattern when it occurs in leads V1 and V2. The type 1 Brugada ECG pattern is diagnostic and is defined as an $\mathrm{rSr}^{\prime}$ with coved ST elevation 
(STE) $\geq 0.2 \mathrm{mV}$, broad $\mathrm{r}^{\prime}$ and inversion of the terminal portion of the $\mathrm{T}$ wave in leads $\mathrm{V} 1-\mathrm{V} 3$.

The type 2 Brugada pattern may, however, be similar to J-point elevation and elevated ST segments observed in healthy athletes. The $\mathrm{r}^{\prime}$ with STE may, however, raise suspicion for the Brugada pattern. Downsloping STE $80 \mathrm{~ms}$ after the ST segment/J point offers a 99\% diagnostic accuracy for the Brugada pattern versus the classic upsloping STE that follows J-point elevation in athletes [65].

Clinical evaluation: Evaluating STE depends on the specific repolarisation pattern, presence of TWI, other pathological ECG abnormalities and the clinical scenario. Isolated J-point elevation in leads V1 and V2 requires no further evaluation. The type 1 Brugada pattern is however, always regarded as pathological. The latest Shanghai Criteria do not recommend evaluation of the type 2 Brugada pattern in the absence of symptoms and family history [39]. In such cases, we suggest repeating the ECG with placement of leads V1 and V2 in the 2nd intercostal space. The conversion of the type 2 pattern to the type 1 pattern with this measure is an indication for confirming the diagnosis with a provocation test with a sodium channel blocking agent [39, 66-68].

\section{Long QT syndrome}

LQTS is associated with adrenergically mediated polymorphic ventricular tachycardia in young individuals. The risk is greatest in individuals with type 1 and 2 LQTS. A consistently prolonged QT interval is one of the hallmarks for LQTS. Repeating an ECG for borderline cases between 470/480 and 500 ms is advisable, whilst prompt referral to a specialist centre is recommended in cases where QTc is constantly $\geq 500 \mathrm{~ms}$. Athletes should ideally be evaluated more than $48 \mathrm{~h}$ after an endurance event because there is an association between endurance exercise and QT prolongation. QT-prolonging medications and electrolyte abnormalities should be actively sought. The assessment of first-degree relatives may aid the diagnosis of LQTS. The Schwartz-Moss score is a useful validated scoring tool which may help evaluate the probability for LQTS, based on ECG parameters (QTc interval, notched T waves, T-wave alterans, torsades de pointes, bradycardia), clinical features (syncope) and family history (first-degree relatives suffering from LQTS or history of early SCD). Paradoxical QT prolongation with increasing heart rate on an exercise test or in the 4th minute of recovery is suggestive of LQTS [1•]. The unparalleled high yield of genetic testing in LQTS, reported up to 75\%, supports the diagnosis of LQTS and also offers the possibility of cascade genetic testing in first-degree relatives [69].

One of the challenges in the diagnosis is the accurate assessment of a long QT interval in athletes. Studies suggest that direct QT measurement is inferior to software-generated values [70], but adhering to the following principles will help ensure otherwise [71].

1. Use Bazett's formula (QT corrected for heat rate $[\mathrm{QTc}]=\mathrm{QT} \mathrm{ms} / \mathrm{square}$ root of the previous RR in seconds).

2. The formula can underestimate QTc if the heart rate is $<60 \mathrm{bpm}$; therefore, mild exercise is advisable to increase the heart rate. The formulae may also overestimate QTC at heart rates > $90 \mathrm{bpm}$; therefore, a repeat ECG after a 
period of resting is advisable to achieve a lower heart rate.

3. An average QT interval in the presence of sinus arrhythmia should be obtained.

4. U waves are common in athletes, especially in the anterior chest leads, and should not be included in the QT assessment. Measuring the QT in leads II and V5 is advisable as these leads often best delineate the end of the T wave.

5. The 'teach the tangent method' is useful in achieving a more accurate QT assessment. By drawing a tangent to the steepest slope of the last limb of the T wave in lead II or V5, the intersection with the baseline is regarded as the end of the T wave.

6. Evaluation of the T-wave morphology (broad, late onset, peaked, notched) is also important and is invaluable in the diagnosis of congenital LQTS in athletes with a prolonged QTc [72].

\section{Premature ventricular complexes}

Premature ventricular complexes (PVC) are reported in $0.7-2.8 \%$ of athletes ECGs $[73,74]$. Complex arrhythmias are present in $4-10 \%$ of athletes with ectopy $[75,76]$. Studies suggest that PVC often disappear during exercise or after periods of deconditioning $[74,75,77]$.

Clinical evaluation: The morphology and complexity of PVCs are two important factors that help predict risk. Complex ventricular arrhythmias increase the risk of structural heart disease up to 15-fold [78]. The origin of the ectopic focus is also important and is determined by the presence of a RBBB or LBBB morphology, along with the location of the precordial R-wave transition. Typically, a PVC with LBBB and inferior axis in V1 suggests a right ventricular outflow tract origin and is traditionally considered benign [79]. Ectopics with a broad RBBB morphology originate from the LV and are more likely to be associated with structural abnormalities [78, 80], highlighting the need for a comprehensive structural assessment in these athletes. It is, however, important to emphasise that not all cases may concur with these general observations; hence, every case should be managed separately. PVCs with a RBBB morphology may also represent a fascicular focus which is classically considered to be benign, rather than implying LV pathology. Conversely, PVCs with a LBBB morphology and inferior axis may be a manifestation of AVC, though a number of factors in QRS morphology may help discern the latter from benign right ventricular outflow tract ectopy [80]. A QRS duration of more than $160 \mathrm{~ms}$, initial QRS slurring, QS pattern in lead V1 and a QRS axis greater than $90^{\circ}$ have been shown to be more common in patients with AVC compared to patients with idiopathic right ventricular outflow tract ectopy [80]. Ultimately, EPS may be necessary to map ectopic foci and risk stratify the clinical phenotype, particularly in cases were ablation may be a therapeutic option.

Athletes with frequent PVCs should undergo comprehensive investigation to exclude structural heart disease, exercise stress testing and prolonged ECG monitoring [81]. Exercise-induced ventricular arrhythmias are regarded as objective markers for adverse cardiac events [82]. The likelihood of structural heart disease is higher in exercise-induced arrhythmias [79], which is why stress testing is an integral part of the evaluation for all those who engage in intense physical activity. 
A PVC burden of $\geq 2000 / 24$ h has been shown to increase the likelihood of structural heart disease [74], with a higher yield of up to $70 \%$ when co-existing with repolarisation abnormalities [83]. A burden exceeding $15 \%$ has generally been reported to confer a higher risk for $\operatorname{LV}$ dysfunction $[76,78]$, which is why comprehensive evaluation of ectopic burden with Holter monitoring and excluding structural heart disease with echocardiography is important, using CMR when clinically relevant.

\section{Conclusion}

Significant advances have been made in improving the sensitivity and specificity of current ECG criteria in athletes [ $1 \bullet$. Subjects with pathological ECG variants may, however, not satisfy current clinical criteria for a suspected phenotype, whilst the relevance of certain patterns are still under investigation. Variable penetrance of some of the disorders in question may, however, complicate matters, which is why current recommendations suggest serial surveillance in athletes with pathological ECG findings [9]. New imaging techniques in combination with more contemporary tools such as genetic testing can contribute towards establishing a clinical diagnosis, predicting prognosis, guiding therapy and offering the opportunity for cascade family screening [84]. Genetic evaluation for instance may one day better define a clinical phenotype.

\section{Compliance with Ethical Standards}

\section{Conflict of Interest}

Mark Abela declares that he has no conflicts of interest. Sanjay Sharma declares that he has no conflict of interest.

Human and Animal Rights and Informed Consent

This article does not contain any studies with human or animal subjects performed by any of the authors.

\section{Open Access}

This article is licensed under a Creative Commons Attribution 4.0 International License, which permits use, sharing, adaptation, distribution and reproduction in any medium or format, as long as you give appropriate credit to the original author(s) and the source, provide a link to the Creative Commons licence, and indicate if changes were made. The images or other third party material in this article are included in the article's Creative Commons licence, unless indicated otherwise in a credit line to the material. If material is not included in the article's Creative Commons licence and your intended use is not permitted by statutory regulation or exceeds the permitted use, you will need to obtain permission directly from the copyright holder. To view a copy of this licence, visit http://creativecommons.org/licenses/by/4.0/. 


\section{References and Recommended Reading}

Papers of particular interest, published recently, have been

highlighted as:

- Of importance

$\bullet$ Of major importance

1. $\quad$ Drezner JA, Sharma S, Baggish A, Papadakis M, Wilson MG, Prutkin JM, et al. International criteria for electrocardiographic interpretation in athletes: consensus statement. Br J Sports Med. 2017;51:704-3.

The latest consensus depicted in this paper provides excellent recommendations into the evaluation of an athlete's ECG, based on the latest evidence.

2. Maron BJ, Gohman TE, Aeppli D. Prevalence of sudden cardiac death during competitive sports activities in Minnesota high school athletes. J Am Coll Cardiol [Internet]. 1998;32(7):1881-4. Available from:. https://doi.org/10.1016/S0735-1097(98)00491-4.

3. Eckart RE, Scoville SL, Campbell CL, Shry EA, Stajduhar KC, Potter RN, et al. Sudden death in young adults: a 25 -year review of autopsies in military recruits. Ann Intern Med. 2004;141(11):829-34.

4. Harmon KG, Asif IM, Klossner D, Drezner JA. Incidence of sudden cardiac death in national collegiate athletic association athletes. Circulation. 2011;123(15):1594600.

5. Maron BJ, Jamshid S, Poliac LC, Mathenge R, Roberts WC, Mueller FO. Sudden death in young competitive athletes - clinical, demographic, and pathological profiles. JAMA [Internet]. 1996;276(3):199-204 Available from: http://jama.jamanetwork.com/article.aspx?doi= 10.1001/jama.1996.03540030033028.

6. Corrado D, Schmied C, Basso C, Borjesson M, Schiavon M, Pelliccia A, et al. Risk of sports: do we need a pre-participation screening for competitive and leisure athletes? Eur Heart J. 2011;32(8):934-44.

7. Corrado D, Basso C, Schiavon M, Pelliccia A, Thiene G. Pre-participation screening of young competitive athletes for prevention of sudden cardiac death. J Am Coll Cardiol. 2008;52(24):1981-9.

8. Corrado D, Basso C, Pavei A, Michieli P, Schiavon MTG. Trends in sudden cardiovascular death in young competitive athletes. Jama. 2006;296(13):1593-601.

9. Malhotra A, Dhutia H, Finocchiaro G, Gati S, Beasley I, Clift $\mathrm{P}$, et al. Outcomes of cardiac screening in adolescent soccer players. N Engl J Med [Internet].

2018;379(6):524-34 Available from: http://www. nejm.org/doi/10.1056/NEJMoa1714719.

10. Pelliccia A, Paolo FMD, Quattrini FM, Basso C, Culasso F, Popoli G, et al. Outcomes in athletes with marked ECG repolarization abnormalities. N Engl J Med. 2008;358(2):152-61.

11. Malhotra A, Dhutia H, Khosla R, Yeo TJ, Narain R, Cassar M, et al. The adolescent athlete's heart according to 3 international criteria: which is best and for which ethnicity? J Am Coll Cardiol [Internet]. 2016;67(13):2357. https://doi.org/10.1016/S0735-
1097(16)32358-0.

This paper supports the importance of serial evaluation of athletes with electrocardiography as a negative screen at baseline does not rule out underlying heart disease.

12. Drezner JA, Ackerman MJ, Anderson J, Ashley E, Asplund CA, Baggish AL, et al. Electrocardiographic interpretation in athletes: the 'Seattle Criteria'. Br J Sports Med. 2013;47:122-4.

13. Dhutia H, Malhotra A, Finocchiaro G, Merghani A, Papadakis M, Naci H, et al. Impact of the international recommendations for electrocardiographic interpretation on cardiovascular screening in young athletes. J Am Coll Cardiol. 2017;70(6):805-7.

14. Merghani A, Malhotra A, Sharma S. The U-shaped relationship between exercise and cardiac morbidity. Trends Cardiovasc Med [Internet]. 2016;26(3):23240. Available from:. https://doi.org/10.1016/j.tcm. 2015.06.005.

15. D'Silva A, Sharma S. Exercise-induced cardiac remodeling: not a case of one size fits all. Circ Cardiovasc Imaging. 2015;8:e004277.

16. Sharma S, Whyte G, Elliott P, Padula M, Kushal R, Mahon N, et al. Electrocardiographic changes in 1000 highly trained junior elite athletes. Br J Sports Med. 2008;33(5):319-24.

17. Brosnan M, La Gerche A, Kalman J, Lo W, Fallon K, Macisaac A, et al. Comparison of frequency of significant electrocardiographic abnormalities in endurance versus nonendurance athletes. Am J Cardiol. 2014;113(9):1567-73.

18. Papadakis M, Basavarajaiah S, Rawlins J, Edwards C, Makan J, Firoozi S, et al. Prevalence and significance of $\mathrm{T}$-wave inversions in predominantly Caucasian adolescent athletes. Eur Heart J. 2009;30(14):1728-35.

19. Zaidi A, Ghani S, Sheikh N, Gati S, Bastiaenen R, Madden B, et al. Clinical significance of electrocardiographic right ventricular hypertrophy in athletes: comparison with arrhythmogenic right ventricular cardiomyopathy and pulmonary hypertension. Eur Heart J. 2013;34(47):3649-56.

20. Calò L, Sperandii F, Martino A, Guerra E, Cavarretta E, Quaranta F, et al. Echocardiographic findings in 2261 peri-pubertal athletes with or without inverted $T$ waves at electrocardiogram. Heart. 2015;101(3):193-200.

21. Gati S, Sheikh N, Ghani S, Zaidi A, Wilson M, Raju H, et al. Should axis deviation or atrial enlargement be categorised as abnormal in young athletes? The athlete's electrocardiogram: time for re-appraisal of markers of pathology. Eur Heart J. 2013;34(47):36418. 
22. Migliore F, Zorzi A, Michieli P, Perazzolo Marra M, Siciliano M, Rigato I, et al. Prevalence of cardiomyopathy in Italian asymptomatic children with electrocardiographic T-wave inversion at preparticipation screening. Circulation [Internet]. 2012;125(3):529-38 Available from: https://www.ahajournals.org/doi/10. 1161/CIRCULATIONAHA.111.055673.

23. Senturk T, Xu H, Puppala K, Krishnan B, Sakaguchi S, Chen LY, et al. Cardiac pauses in competitive athletes: a systematic review examining the basis of current practice recommendations. Europace. 2016;18:1873-9.

24. Pelliccia A, Fagard R, Bjørnstad HH, Anastassakis A, Arbustini E, Assanelli D, et al. Recommendations for competitive sports participation in athletes with cardiovascular disease. Med dello Sport. 2005;58(3):15791.

25. Klein GJ, Prystowsky EN, Yee R, Sharma AD, Laupacis A. Asymptomatic Wolff-Parkinson-White. Should we intervene? Circulation. 1989;80:1902-5.

26. Panhuyzen-goedkoop N, Corrado D. Recommendations for participation in leisure-time physical activity and competitive sports in patients with arrhythmias and potentially arrhythmogenic conditions part I: supraventricular arrhythmias and pacemakers of the study group on sports cardiology. Eur J Cardiovasc Prev Rehabil. 2006;13(4):475-84.

27. Rao AL, Salerno JC, Asif IM. Evaluation and management of Wolff-Parkinson-White in athletes. Sport Heal A Multidiscip Approach. 2014;6(4):326-32.

28. Li X, Cui S, Xuan D, Xuan C, Xu D. Atrial fibrillation in athletes and general population. Medicine (Baltimore). 2018;97(49):1-8

29. Ehtisham J, Watkins H. Is Wolff-Parkinson-White syndrome a genetic disease? J Cardiovasc Electrophysiol. 2005;16(11):1258-62.

30. Banankhah P, Fishbein GA, Dota A, Ardehali R. Cardiac manifestations of PRKAG2 mutation. BMC Med Genet. 2018;19(1):17-20.

31. Pöyhönen P, Hiippala A, Ollila L, Kaasalainen T, Hänninen $\mathrm{H}$, Heliö $\mathrm{T}$, et al. Cardiovascular magnetic resonance findings in patients with PRKAG2 gene mutations. J Cardiovasc Magn Reson [Internet]. 2015;17(1). Available from:). https://doi.org/10.1186/ s12968-015-0192-3.

32. Cohen MI, Triedman JK, Cannon BC, Davis AM, Drago F, Janousek J, et al. PACES/HRS expert consensus statement on the management of the asymptomatic young patient with a Wolff-Parkinson-White (WPW, ventricular preexcitation) electrocardiographic pattern. Hear Rhythm [Internet]. 2012;9(6):1006-24 Available from: https://linkinghub.elsevier.com/retrieve/pii/ S1547527112002937.

33. Daubert C, Ollitrault J, Descaves C, Mabo P, Ritter P, Gouffault J. Failure of the exercise test to predict the anterograde refractory period of the accessory pathway in Wolff Parkinson White syndrome. Pacing Clin Electrophysiol [Internet]. 1988;11(8):1130-8 Available from: http://www.ncbi.nlm.nih.gov/pubmed/ 2459665 .
34. Klein GJ, Gulamhusein SS. Intermittent preexcitation in the Wolff-Parkinson-White syndrome. Am J Cardiol [Internet]. 1983;52(3):292-6 Available from: http:// www.ncbi.nlm.nih.gov/pubmed/6869275.

35. Bent RE, Wheeler MT, Hadley D, Froelicher V, Ashley E, Perez MV. Computerized Q wave dimensions in athletes and hypertrophic cardiomyopathy patients. J Electrocardiol. 2015;48:362-7.

36. Sheikh N, Papadakis M, Ghani S, Zaidi A, Gati S, Adami PE, et al. Comparison of electrocardiographic criteria for the detection of cardiac abnormalities in elite black and white athletes. Circulation.

2014;129(16):1637-49.

37. Bonakdar H, Moladoust H, Kheirkhah J, Abbaspour E, Rad MA, Salari A, et al. Significance of a fragmented QRS complex in patients with chronic total occlusion of coronary artery without prior myocardial infarction. Anatol J Cardiol. 2015:106-12.

38. Haukilahti MAE, Eranti A, Kenttä T, Huikuri HV. QRS fragmentation patterns representing myocardial scar need to be separated from benign normal variants: hypotheses and proposal for morphology based classification. Front Physiol. 2016;7(653):1-10.

39. Antzelevitch C, Yan G-X, Ackerman MJ, Borggrefe M, Corrado D, Guo J, et al. J-wave syndromes expert consensus conference report: emerging concepts and gaps in knowledge. J Arrhythmia [Internet]. 2016;32(5):315-39 Available from: http://linkinghub. elsevier.com/retrieve/pii/S1880427616300734.

40. Virk HUH, Farooq S, Ghani AR, Arora S. QRS fragmentation: its role in sherlocking the arrhythmogenic heart. J Community Hosp Intern Med Perspect [Internet]. 2016;6(3):31235 Available from: http://www. ncbi.nlm.nih.gov/pubmed/27406448.

41. Pei J, Li N, Gao Y, Wang Z, Li X, Zhang Y, et al. The J wave and fragmented QRS complexes in inferior leads associated with sudden cardiac death in patients with chronic heart failure. Europace [Internet]. 2012;14(8):1180-7 Available from: https://academic. oup.com/europace/article-lookup/doi/10.1093/ europace/eur437.

42. Morita H, Watanabe A, Morimoto Y, Kawada S, Tachibana M, Nakagawa K, et al. Distribution and prognostic significance of fragmented QRS in patients with Brugada syndrome. Circ Arrhythmia

Electrophysiol [Internet]. 2017;10(3):e004765 Available from: https://www.ahajournals.org/doi/10.1161/ CIRCEP.116.004765.

43. Peters S, Trümmel M, Koehler B. QRS fragmentation in standard ECG as a diagnostic marker of arrhythmogenic right ventricular dysplasia-cardiomyopathy. Hear Rhythm [Internet]. 2008;5(10):1417-21 Available from: https://linkinghub.elsevier.com/retrieve/ pii/S1547527108006863.

44. Usoro AO, Bradford N, Shah AJ, Soliman EZ. Risk of mortality in individuals with low QRS voltage and free of cardiovascular disease. Am J Cardiol [Internet]. 2014;113(9):1514-7 Available from: https:// 
linkinghub.elsevier.com/retrieve/pii/ S0002914914006298.

45. Zorzi A, Marra MP, Rigato I, De Lazzari M, Susana A, Niero A, et al. Nonischemic left ventricular scar as a substrate of life-threatening ventricular arrhythmias and sudden cardiac death in competitive athletes. Circ Arrhythm Electrophysiol. 2016;9(7):1-14.

46. Desai AD, Yaw TS, Yamazaki T, Kaykha A, Chun S, Froelicher VF. Prognostic significance of quantitative QRS duration. Am J Med. 2006;119(7):600-6.

47. Aro AL, Anttonen O, Tikkanen JT, Junttila MJ, Kerola T, Rissanen HA, et al. Intraventricular conduction delay in a standard 12-lead electrocardiogram as a predictor of mortality in the general population. Circ Arrhythm Electrophysiol. 2011;4(5):704-10.

48. Chandra N, Bastiaenen R, Papadakis M, Panoulas VF, Ghani S, Duschl J, et al. Prevalence of electrocardiographic anomalies in young individuals: relevance to a nationwide cardiac screening program. J Am Coll Cardiol. 2014;63(19):2028-34.

49. Calore C, Zorzi A, Sheikh N, Nese A, Facci M, Malhotra $\mathrm{A}$, et al. Electrocardiographic anterior T-wave inversion in athletes of different ethnicities: differential diagnosis between athlete's heart and cardiomyopathy. Eur Heart J. 2016;37(32):2515-27.

50. Schnell F, Riding N, O'Hanlon R, Lentz PA, Donal E, Kervio G, et al. Recognition and significance of pathological T-wave inversions in athletes. Circulation. 2015;131(2):165-73.

51. Papadakis M, Carre F, Kervio G, Rawlins J, Panoulas VF, Chandra $\mathrm{N}$, et al. The prevalence, distribution, and clinical outcomes of electrocardiographic repolarization patterns in male athletes of African/AfroCaribbean origin. Eur Heart J. 2011;32(18):2304-13.

52. Malhotra A, Yeo J, Dores H, Bastiaenen R, Narain R, Merghani A, et al. Anterior T-wave inversion in young White athletes and nonathletes prevalence and significance. J Am Coll Cardiol. 2017;69(1):1-9.

53. Page SEE. Anterior T-wave inversion does not convey short-term sudden death risk. J Am Coll Cardiol [Internet]. 2017;69(1):10-2. Available from. https://doi. org/10.1016/j.jacc.2016.11.011.

54. Mcclean G, Riding NR, Pieles G, Sharma S, Watt V, Adamuz C, et al. Prevalence and significance of T-wave inversion in Arab and black paediatric athletes; should anterior T-wave inversion interpretation be governed by biological or chronological age? Eur J Prev Cardiol. 2019;26(6):641-52.

55. Wilson MG, Drezner JA, Sharma S. IOC manual of sports cardiology. First Edit: Wiley Blackwell Publishing House; 2017.

56. Basu J, Malhotra A, Styliandis V, Dhutia H, Miles C, Parry-Williams G, et al. Prevalence and progression of the juvenile pattern in the electrocardiogram of adolescents. Heart. 2018;104(Suppl 6):A1-118.

57. Magalski A, Maron BJ, Main ML, McCoy M, Florez A, Reid KJ, et al. Relation of race to electrocardiographic patterns in elite American football players. J Am Coll Cardiol. 2008;51(23):2250-5.
58. Zorzi A, Migliore F, Ph D, Elmaghawry M, Silvano M, Marra MP, et al. Electrocardiographic predictors of electroanatomic scar size in arrhythmogenic right ventricular cardiomyopathy : implications for arrhythmic risk stratification. J Cardiovasc Electrophysiol. 2013;24:1321-7.

59. D'Ascenzi F, Pelliccia A, Valentini F, Malandrino A, Natali BM, Barbati R, et al. Training-induced right ventricular remodelling in pre-adolescent endurance athletes: the athlete's heart in children. Int J Cardiol [Internet]. 2017;236:270-5. Available from:. https:// doi.org/10.1016/j.ijcard.2017.01.121.

60. Brosnan MJ, Claessen G, Heidbuchel H, Prior DL, La Gerche A. Right precordial T-wave inversion in healthy endurance athletes can be explained by lateral displacement of the cardiac apex. JACC Clin Electrophysiol. 2015;1(1-2):84-91.

61. Zaidi A, Sheikh N, Jongman JK, Gati S, Panoulas VF, Carr-White G, et al. Clinical differentiation between physiological remodeling and arrhythmogenic right ventricular cardiomyopathy in athletes with marked electrocardiographic repolarization anomalies. J Am Coll Cardiol. 2015;65(25):2702-11.

62. Finocchiaro G, Papadakis M, Dhutia H, Zaidi A, Malhotra A, Fabi E, et al. Electrocardiographic differentiation between "benign T-wave inversion" and arrhythmogenic right ventricular cardiomyopathy. Europace. 2019;21(2):332-8.

63. Marcus FI, Mckenna WJ, Sherrill D, Basso C, Bauce B, David A, et al. Diagnosis of arrhythmogenic right ventricular cardiomyopathy/dysplasia. Circulation. 2010;121:1533-41.

64. Miles C, Finocchiaro G, Papadakis M, Gray B, Westaby J, Ensam B, et al. Sudden death and left ventricular involvement in arrhythmogenic cardiomyopathy. Circulation. 2019;139(15):1786-97.

65. Zorzi A, Leoni L, Di Paolo FM, Rigato I, Migliore F, Bauce B, et al. Differential diagnosis between early repolarization of athlete's heart and coved-type Brugada electrocardiogram. Am J Cardiol. 2015;115(4):529-32.

66. Matusik PT, Komar M, Podolec J, Karkowski G, Lelakowski J, Podolec P. Exercise ECG unmasked Brugada sign: manifestation of the risk of sportsassociated sudden cardiac arrest (RCD code: V-1A. 1). JRCD. 2017;3(3):92-7.

67. Masrur S, Memon S, Thompson PD. Brugada syndrome, exercise, and exercise testing. Clin Cardiol. 2015;38(5):323-6.

68. Steinfurt J, Biermann J, Bode C, Odening KE. The diagnosis, risk stratification, and treatment of Brugada syndrome. Dtsch Arztebl Int. 2015;112(23):394-401.

69. Kapa S, Tester DJ, Salisbury BA, Harris-kerr C, Pungliya MS, Alders M, et al. Genetic testing for long-QT syndrome distinguishing pathogenic mutations from benign variants. Circulation. 2009;2009(120):1752-60.

70. Viskin S, Rosovski U, Sands AJ, Chen E, Kistler PM, Kalman JM, et al. Inaccurate electrocardiographic interpretation of long QT: the majority of physicians 
cannot recognize a long QT when they see one. Heart Rhythm. 2005;2(6):569-74.

71. Postema PG, De Jong JSSG, Van der Bilt IAC, Wilde AAM. Accurate electrocardiographic assessment of the QT interval: teach the tangent. Heart Rhythm. 2008;5(7):1015-8.

72. Malfatto G, Beria G, Sala S, Bonazzi O, Schwartz PJ. Quantitative analysis of T wave abnormalities and their prognostic implications in the idiopathic long QT syndrome. J Am Coll Cardiol. 1994;23(2):296-301.

73. Marek J, Bufalino V, Davis J, Marek K, Gami A, Stephan $\mathrm{W}$, et al. Feasibility and findings of large-scale electrocardiographic screening in young adults: data from 32,561 subjects. Heart Rhythm. 2011;8:1555-9.

74. Biffi A, Pelliccia A, Verdile L, Fernando F, Spataro A, Caselli $\mathrm{S}$, et al. Long-term clinical significance of frequent and complex ventricular tachyarrhythmias in trained athletes. J Am Coll Cardiol [Internet]. 2002;40(3):446-52 Available from: http://www.ncbi. nlm.nih.gov/pubmed/12142109.

75. Verdile L, Maron BJ, Pelliccia A, Spataro A, Santini M, Biffi A. Clinical significance of exercise-induced ventricular tachyarrhythmias in trained athletes without cardiovascular abnormalities. Heart Rhythm. 2015;12(1):78-85.

76. Lee YH, Zhong L, Roger VL, Asirvatham SJ, Shen WK, Slusser JP, et al. Frequency, origin, and outcome of ventricular premature complexes in patients with or without heart diseases. Am J Cardiol. 2014;114(9):1373-8.

77. Biffi A, Maron BJ, Verdile L, Fernando F, Spataro A, Marcello G, et al. Impact of physical deconditioning on ventricular tachyarrhythmias in trained athletes. J Am Coll Cardiol [Internet]. 2004;44(5):1053-8. Available from:. https://doi.org/10.1016/j.jacc.2004.05.065.

78. Sadron Blaye-Felice M, Hamon D, Sacher F, Pascale P, Rollin A, Duparc A, et al. Premature ventricular contraction-induced cardiomyopathy: related clinical and electrophysiologic parameters. Heart Rhythm. 2016;13(1):103-10.

79. Park KM, Kim YH, Marchlinski FE. Using the surface electrocardiogram to localize the origin of idiopathic ventricular tachycardia. PACE - Pacing Clin

Electrophysiol. 2012;35(12):1516-27.

80. Novak J, Zorzi A, Castelletti S, Pantasis A, Rigato I, Corrado D, et al. Electrocardiographic differentiation of idiopathic right ventricular outflow tract ectopy from early arrhythmogenic right ventricular cardiomyopathy. Europace. 2017;19(4):622-8.

81. D'Silva A, Sharma S. Management of mature athletes with cardiovascular conditions. Heart.

2018;104(13):1125-34.

82. Morshedi-Meibodi A, Evans JC, Levy D, Larson MG, Vasan RS. Clinical correlates and prognostic significance of exercise-induced ventricular premature beats in the community: the Framingham heart study. Circulation. 2004;109(20):2417-22.

83. Corrado D, Pelliccia A, Bjørnstad HH, Vanhees L, Biffi A, Borjesson $\mathrm{M}$, et al. Cardiovascular pre-participation screening of young competitive athletes for prevention of sudden death: proposal for a common European protocol - Consensus Statement of the Study Group of Sport Cardiology of the Working Group of Cardiac Rehabilitation and Exercise Physiology and the Working Group of Myocardial and Pericardial Diseases of the European Society of Cardiology. Eur Heart J. 2005;26(5):516-24.

84. Ackerman MJ, Priori SG, Willems S, Berul C, Brugada R, Calkins $\mathrm{H}$, et al. HRS/EHRA expert consensus statement on the state of genetic testing for the channelopathies and cardiomyopathies. Hear Rhythm [Internet]. 2011;8(8):1308-39 Available from: https://

linkinghub.elsevier.com/retrieve/pii/ S1547527111006072.

\section{Publisher's Note}

Springer Nature remains neutral with regard to jurisdictional claims in published maps and institutional affiliations. 